\title{
¿Se acude menos a consulta en un entorno de crisis económica?
}

\section{Do people go to the doctor less in times of economic crisis?}

\author{
J. J. Mira ${ }^{1}$, S. Lorenzo ${ }^{2}$
}

\section{Sr. Director:}

España ${ }^{1}$ ocupa el sexto puesto por detrás de Japón, República Checa, Hungría, Corea y Eslovaquia, con una media de 9,5 consultas al médico por persona (media OCDE 6,8). Sin embargo, en los últimos meses podría estar produciéndose, en opinión de algunos gestores y clínicos, un descenso en la presión en urgencias, consultas y en las listas de espera quirúrgica de procesos demorables, relacionada con la actual crisis económica y el miedo a la pérdida de empleo que la acompaña.

La frecuentación a consultas o urgencias podría ser un indicador indirecto para aproximarse a este fenómeno. En la frecuentación cabe esperar que influyan: situación laboral, edad, estado civil o sexo entre otros factores ${ }^{2}$. Habitualmente, por ejemplo, la frecuentación es mayor entre empleados por cuenta ajena que entre autónomos. También se ha señalado que la autopercepción de salud sería un antecedente de la búsqueda de atención médica ${ }^{3}$.

En este estudio observacional, descriptivo, transversal, basado en entrevistas, se analizó esta cuestión, considerando como variable moduladora la autopercepción de salud. La frecuentación se consideró baja: 1 visita/año; media: hasta 2 visitas/año; o alta: 5 o más visitas/año en los últimos 12 meses. En total se realizaron 192 entrevistas personales estructuradas válidas (tasa de respuesta del 95\%). El tamaño muestral fue calculado para una $\mathrm{p}=0,5$, error del $3 \%$ y un nivel de confianza del 95\%. Se incrementó el tamaño muestral para una esperanza de respuesta del 85\%. La muestra correspondió a residentes en 3 comunidades autónomas que acudieron a Consultas Externas o Urgencias hospitalarias.

La muestra estuvo constituida por 76 varones $(39,6 \%)$ y 116 mujeres $(60,4 \%) ; 107$ mayores de 50 años (56\%). En esta muestra la mayoría, 124, habían cursado estudios primarios $(64,9 \%) ; 82(42,5 \%)$ estaban desempleados o jubilados. La mayoría, 153, residían en zona urbana $(79,3 \%)$.

En 99 casos $(51,3 \%)$ se valoró la propia salud como buena y en $66(34,2 \%)$ como regular. En 37 casos (19,3\%) los entrevistados informaron que en el último año habían
1. Universidad Miguel Hernández. Departamento Salud 17. Consellería Sanitat. CIBER Epidemiología y Salud Pública (CIBERESP).

2. Hospital Universitario Fundación Alcorcón.

Recepción: 30 de agosto de 2011

Aceptación provisional: 7 de septiembre de 2011

Aceptación definitiva: 8 de septiembre de 2011

\section{Correspondencia:}

José Joaquín Mira Solves

Universidad Miguel Hernández

Avda. Universidad, s/n

03202 Elche (Alicante)

E-mail: jose.mira@umh.es 
acudido a consultas médicas una sola vez, 111 casos $(57,5 \%)$ entre 2 y 4 veces, mientras que $44(22,8 \%)$ dijeron haber acudido 5 o más veces. Hombres y mujeres acudieron a consultas un número similar de veces $\left(\chi^{2}=5,1, p=0,08\right)$, si bien se observó una mayor frecuentación entre las mujeres de mayor edad $\left(\chi^{2}=6,4, p=0,04\right)$. La autopercepción de salud se identificó como un antecedente de la frecuentación en el último año ( $B=3,0$, IC95\% 2,6-3,4). Una pobre percepción de salud coincidía con una mayor frecuentación y en esta submuestra se observaba hasta un $56 \%$ de pacientes que acudían a consulta 5 o más veces al año. La mayor frecuentación cuando la autopercepción de salud era buena se produjo entre desempleados y jubilados $\left(\chi^{2}=27,4\right.$, p $<0,001)$. Ahora bien, cuando la autopercepción de salud era positiva la alta frecuentación seguía en un 15,3\% de los casos. Todos estos datos confirman las tendencias conocidas.

También como cabía esperar, la frecuentación fue mayor entre desempleados (sobre todo de mayor edad) y jubilados $\left(\chi^{2}=12,6, p=0,04\right)$. Pero curiosamente, en esta muestra, los autónomos dijeron acudir más veces a consulta en el último año que los empleados por cuenta ajena (33,3\% vs $16,7 \%)$, y cuando consideramos solo a quienes manifestaron tener una buena salud, el número de autónomos duplicó al de empleados por cuenta ajena entre quienes dijeron acudir a consulta 5 o más veces al año (29\% vs $14 \%)$.

Los resultados confirman las tendencias esperadas. La frecuentación -demanda- está condicionada por múltiples factores $^{2-6}$ : gratuidad, el tipo de población que condiciona diferentes tipos de enfermedades, la organización de la asistencia primaria, la proximidad del hospital, la edad, la morbilidad o una pobre autopercepción de salud, aunque esta relación no sea lineal y aún en el caso de una autopercepción de salud positiva exista un volumen de pacientes que muestran una moderada o incluso alta frecuentación.

Los resultados de este estudio refuerzan la impresión de gestores y clínicos acerca de la disminución de la demanda de atención sanitaria entre empleados, aunque requiere de un estudio en mayor profundidad para confirmar esta tendencia, discernir sus posibles causas, y también sus consecuencias en términos de costes de salud para los individuos y para el propio sistema.

\section{BIBLIOGRAFÍA}

1. OECD Health Data 2007. Disponible en http://www.oecd-ilibrary.org/social-issuesmigration-health/data/oecd-health-statistics/oecd-health-data-health-status_data-00540-en; jsessionid $=27$ ekvsc $1 \mathrm{~d} 6 \mathrm{qbj}$. epsilon?isPartOf=/content/datacollection/ health-data-en

2. Gómez Calcerrada D, Hernández del Pozo F, GóMEz BERROCAL M. La investigación en la utilización de servicios sanitarios. FMC Aten Primaria 1996; 3: 229-241.

3. Luciano JV, Serrano A, Grupo DASMAP. Los hiperfrecuentadores en atención primaria: perfil sociodemográfico, características clínicas y propuesta de una nueva definición. Aten Primaria. 2008; 40: 631-632.

4. Asenjo MA. Gestión diaria del hospital. $3^{\mathrm{a}}$ ed. Elsevier, Barcelona 2006.

5. FRIES JF. Aging, natural death, and the compression of morbidity. N Engl J Med.1980; 303: 130-135.

6. Castells X, LlucMercadÉ X, Riu M. Envejecimiento y utilización hospitalaria. Informe SESPAS 2002. Disponible en:http://www.sespas.es. 